\title{
Lessons learnt from implementing an empirically informed recruitment approach for FEM-PrEP, a large HIV prevention clinical trial
}

This article was published in the following Dove Press journal:

Open Access Journal of Clinical Trials

19 December 2014

Number of times this article has been viewed

\author{
Caleb Parker ${ }^{1}$ \\ Amy Corneli' \\ Kawango Agot ${ }^{2}$ \\ Jacob Odhiambo ${ }^{2}$ \\ Jesse Asewe ${ }^{2}$ \\ Khatija Ahmed ${ }^{3}$ \\ Joseph Skhosana ${ }^{3}$ \\ Malebo Ratlhagana ${ }^{3}$ \\ Michele Lanham' \\ Christina Wong' \\ Jennifer Deese' \\ Rachel Manongi ${ }^{4}$ \\ Lut Van Damme'
}

\section{On behalf of the FEM-PrEP \\ recruitment group}

'FHI 360, Global Health, Population and Nutrition, Durham, NC, USA;

${ }^{2}$ Impact Research and Development Organization, Kisumu, Kenya;

${ }^{3}$ Setshaba Research Centre,

Soshanguve, Pretoria, South Africa;

${ }^{4}$ Kilimanjaro Christian Medical Centre, Moshi, Tanzania
Correspondence: Caleb Parker FHI 360, 359 Blackwell Street, Suite 200, Durham, NC 2770I, USA

$\mathrm{Tel}+$ I 9195447040

Fax + I 919544726 I

Email cparker@fhi360.org
Abstract: We implemented an empirically informed, geographically based recruitment approach for FEM-PrEP, a human immunodeficiency virus (HIV) prevention clinical trial of daily oral emtricitabine (FTC) and tenofovir disoproxil fumarate (TDF) for HIV prevention. During the formative research phase, we conducted a modification of the Priorities for Local AIDS Control Efforts (PLACE) method and used those data and staff experiences to identify and prioritize for recruitment geographic areas where HIV incidence might be high. During the clinical trial, we implemented a routinely monitored and flexible recruitment plan in the geographical areas identified in the formative research. We describe three lessons learnt from implementing this approach: 1) the PLACE data were critical in identifying places presumed to be high risk; 2) staff experiences, in combination with PLACE data, were needed to inform a practical recruitment strategy; and 3) recruiting in establishments in priority areas identified by the PLACE data led to screening many HIV-positive women at the Bondo site (Kenya), placing additional burden on clinic staff. These lessons learnt highlight the critical importance of having a flexible and monitored recruitment strategy. Although we successfully recruited a study population at higher risk for HIV, FEM-PrEP was unable to determine the effectiveness of FTC/TDF for HIV prevention, due to low adherence to the study product among participants. We must shift the paradigm of recruitment for clinical trials of new products from focusing on identifying populations with high incidence to identifying populations at risk who are motivated and able to adhere to the study product regimen.

Keywords: recruitment, PrEP, PLACE, FEM-PrEP, HIV prevention clinical trial, women

\section{Introduction}

Human immunodeficiency virus (HIV) prevention clinical trials are implemented among populations in need of alternative HIV prevention options and typically in geographic areas with sufficient HIV incidence to answer the trial's primary efficacy question. Such populations, however, can be challenging to identify and recruit into clinical trials. Recruitment approaches reported most often in pre-exposure prophylaxis (PrEP), vaginal microbicide, and HIV vaccine clinical trials include recruiting from community venues such as markets, education institutions, bars, and hotels/hostels, ${ }^{1-7}$ from health facilities such as family planning, sexually transmitted infection (STI), and primary care clinics, ${ }^{4-11}$ through peer recruiters, $;, 6,11$ and through strategies combining geography and sexual network characteristics. ${ }^{12}$

We chose to use an empirically informed, geographically based approach to develop the recruitment strategy for FEM-PrEP, an FHI 360-sponsored clinical trial to assess the safety and effectiveness of once-daily oral emtricitabine (FTC) and tenofovir disoproxil 
fumarate (TDF) for HIV prevention. The trial was conducted among women who were at higher risk of acquiring HIV in Bondo, Kenya; Bloemfontein and Pretoria, South Africa; and Arusha, Tanzania. We began planning for FEM-PrEP soon after the completion of the SAVVY trials in West Africa, also sponsored by FHI 360. ${ }^{1,2}$ Investigators from these trials reported that they were unable to determine the effectiveness of the study product because of lower than expected HIV incidence within the study population. With this in mind, and building upon FHI 360's previous PrEP clinical trial formative research, we conducted formative research in three of the four FEM-PrEP sites (Bondo, Pretoria, and Arusha) to inform the FEM-PrEP recruitment strategy by identifying places where HIV incidence might be high. ${ }^{13}$ (We did not conduct formative research in the Bloemfontein site because FHI 360 had recently completed an incidence study there and we intended to recruit from that study population). As part of the formative research, we used a modification of the Priorities for Local AIDS Control Efforts (PLACE) method $^{14}$ to gather data to inform our recruitment strategy and asked participants where would be appropriate places to recruit women who engage in activities that put them at higher risk for HIV.

The PLACE method, originally designed to monitor, inform, and improve HIV prevention programs, uses a systematic series of interviews conducted in the community to identify venues and establishments - such as bars, shops, and hotels - within a geographic area where people at high risk of HIV and STIs are found and where HIV incidence might be high. It is a quick, affordable, and easy data collection process and is based on the premises that new HIV infections are often concentrated in particular geographic areas and that new sexual partnerships drive the HIV epidemic. ${ }^{14,15}$ Several studies have successfully identified individuals who are at high risk of HIV using the PLACE method, ${ }^{16-19}$ and PLACE has been more effective at identifying high-risk populations compared with other available data sources. ${ }^{20,21}$

In this manuscript, we describe how we implemented a modified version of the PLACE method during the formative research and then applied those data to inform FEM-PrEP's recruitment strategy. We also describe lessons learnt from implementing this empirically informed recruitment approach.

\section{Development of the FEM-PrEP strategic recruitment plan}

The formative research phase was reviewed and approved by the ethics committees at the Kilimanjaro Christian Medical
College and the National Institute of Medical Research in Tanzania (Arusha), the Kenyatta National Hospital/University of Nairobi Research and Ethics Committee in Kenya (Bondo), the Medunsa Campus Research Ethics Committee in South Africa (Pretoria), and the Protection of Human Subjects Committee at FHI 360 in the US. All participants provided either oral or written consent, per local ethics guidelines. The FEM-PrEP clinical trial was reviewed and approved by all associated ethics and regulatory committees, and all trial participants provided written informed consent. All data collected during the trial were collected in accordance with Good Clinical Trial Practice.

Site teams prepared for data collection during the formative research by listing the geographic areas or villages within the site's catchment area where they believed women at higher risk for HIV could be found. They considered the following: 1) areas where women who are at higher risk of HIV work or live; 2) areas with a high number of bars, hotels, and other places where people meet sexual partners; 3) areas with a high population density; and 4) areas near the study clinic. The list was shared with the site's community advisory board (CAB) to confirm that these areas were indeed locations that would be appropriate for recruitment for FEM-PrEP.

Following the PLACE method's approach to data collection, we interviewed a convenience sample of community members in public places from the geographic areas previously identified by staff members and confirmed by the CAB, asking community members to identify establishments where people go to meet new sexual partners. Next, we confirmed the existence of the establishments mentioned most often and interviewed their owners and managers to learn more about the specific establishments and the behaviors of people who socialize there. Then, we interviewed a convenience sample of women and men socializing at the establishment - as well as women who worked there - about their sexual behaviors (eg, the number of new and returning sexual partners in the past 4 weeks) and how often they come to the establishment. The geographic location of each establishment where interviews were conducted was collected using a global positioning system (GPS) unit. After data collection was completed, we combined interview and GPS data to rank geographic areas for recruitment. We initially planned a 6-month data collection period, with two to three interviewers at each site. This time period was extended, however, as we waited for approvals to initiate the clinical trial. Interviewers - including additional staff who had 
completed other formative research activities - continued to conduct interviews and collect GPS data in additional locations as time allowed.

To illustrate the process, we describe here the results of PLACE data collection at the Arusha site and how those data informed the site's strategic recruitment plan. Community members identified 292 establishments as venues where people meet sexual partners. Of the identified establishments, 127 (43\%) were repeatedly mentioned by community members as places where high-risk sexual activities occur and were confirmed to exist. We then conducted 211 surveys with men and 330 with women who were employees or patrons in these establishments. GPS coordinates were collected at 75 of the establishments (Figure 1); GPS coordinates were not collected in 44 establishments because the women and men who were interviewed there reported fewer risk behaviors compared with the other establishments. GPS coordinates were also not collected for an additional eight establishments because of logistical barriers.

We then plotted the locations of the 75 establishments on a map of Arusha using ArcGIS v10,22 a geographic information system (GIS). The individual interview data from each establishment were then aggregated by respondent type and linked to the associated establishment. Next, we created nine establishment clusters by grouping together establishments of close proximity and those patronized by similar numbers of people on the busiest night of the week (Figure 2). We then compared sexual behaviors by cluster, and prioritized them for recruitment based on risk factors for HIV and the number of women employed at and/or patronizing the establishments (Table 1). Clusters that had higher frequencies on these variables were prioritized toward the beginning of the ranking list (Figure 3). Cluster $\mathrm{A}$, for example, was given first priority for recruitment because it had a higher number of high-risk activities relative to other clusters: 1) women in

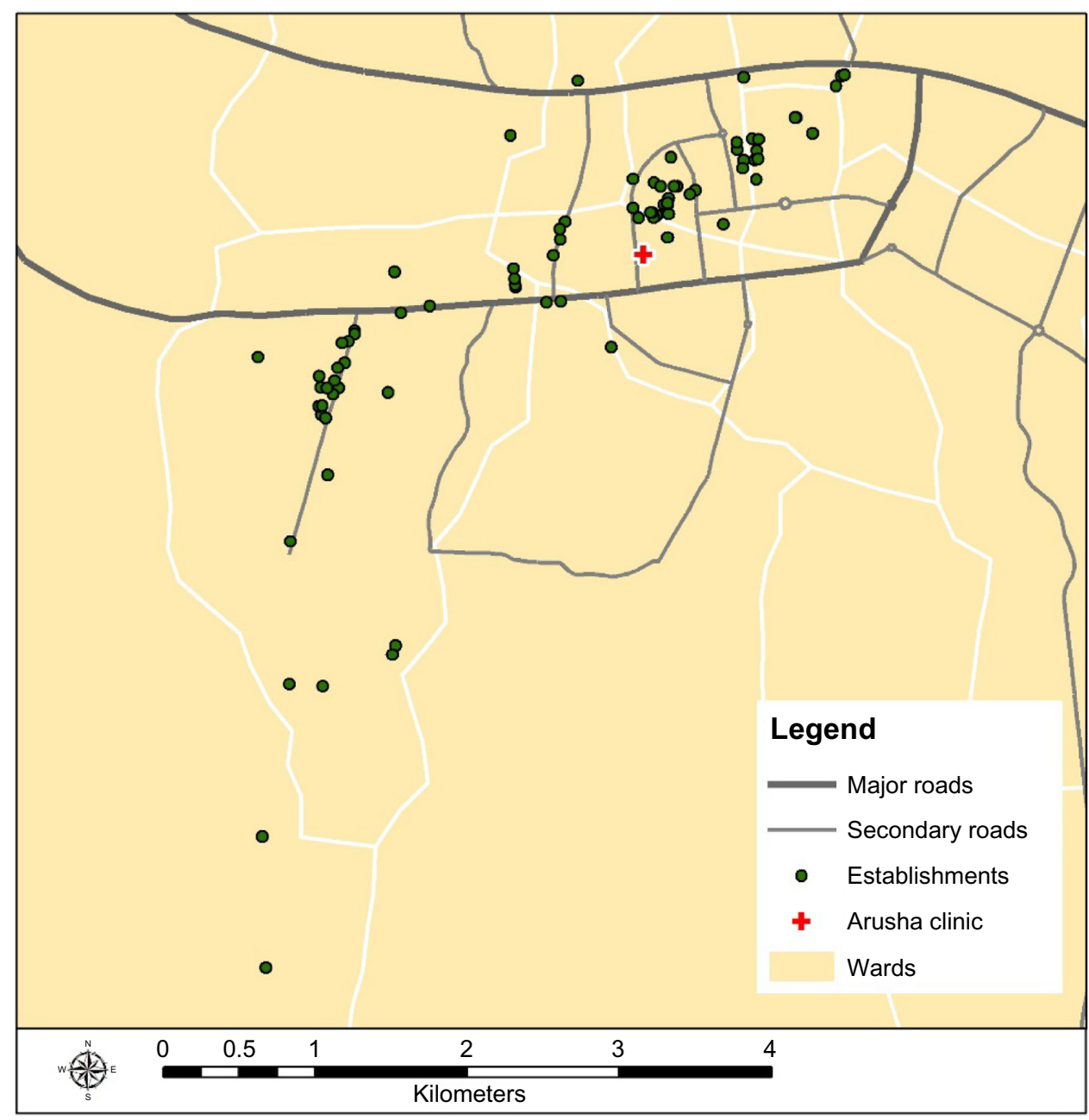

Figure I Location of establishments in Arusha, Tanzania.

Notes: Road network data created by OpenStreetMap, (C) OpenStreetMap contributors. ${ }^{28}$ Administrative boundary data accessed from DIVA-GIS. ${ }^{29}$ 


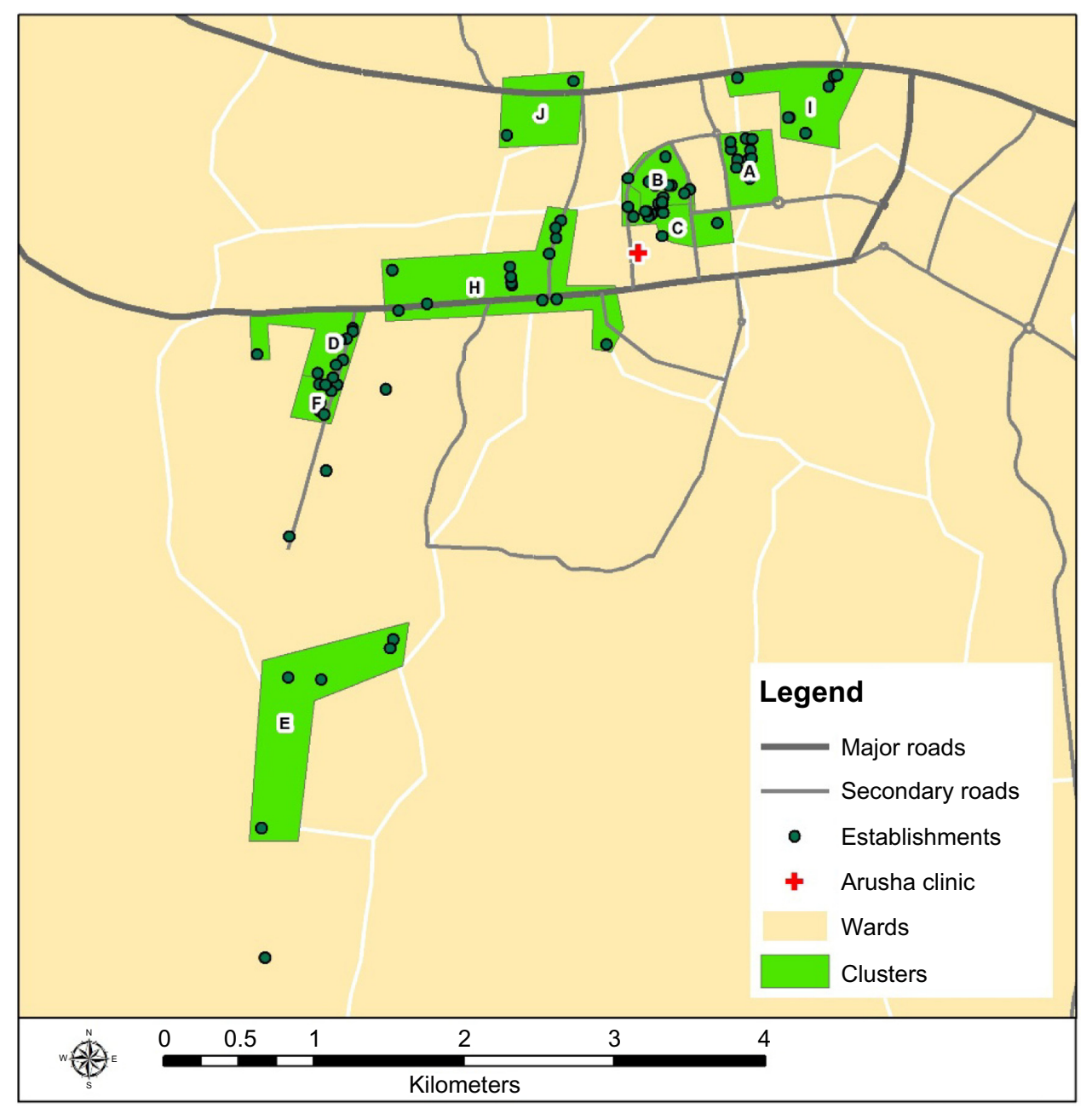

Figure 2 Establishment clusters in Arusha, Tanzania.

Notes: Road network data created by OpenStreetMap, (C) OpenStreetMap contributors. ${ }^{28}$ Administrative boundary data accessed from DIVA-GIS. ${ }^{29}$

Table I Prioritization of establishment clusters in Arusha, Tanzania

\begin{tabular}{|c|c|c|c|c|c|c|c|c|c|c|}
\hline Cluster & $\mathbf{A}$ & B & C & $\mathbf{D}$ & $\mathbf{E}$ & $\mathbf{F}$ & $\mathbf{H}$ & $\mathbf{I}$ & $J$ & Total \\
\hline Number of establishments & 11 & 13 & 9 & 8 & 4 & 7 & 14 & 7 & 2 & 75 \\
\hline $\begin{array}{l}\text { Average number of guests at each } \\
\text { establishment on busiest night }\end{array}$ & $<25$ & $<50$ & $<50$ & $<50$ & $<50$ & $<50$ & $<50$ & $<50$ & $<50$ & \\
\hline $\begin{array}{l}\text { Total guests at all bars in cluster } \\
\text { on busiest night }{ }^{\mathrm{a}}\end{array}$ & 374 & 707 & 548 & 358 & 150 & 264 & 654 & 309 & 352 & 3,716 \\
\hline $\begin{array}{l}\text { Women's average sex partners } \\
\text { in past } 4 \text { weeks }\end{array}$ & 5.3 & 2.2 & 4.4 & 1.9 & 1.4 & 2.5 & 2.6 & 1.9 & 3 & 2.8 \\
\hline $\begin{array}{l}\text { Women's average new sex } \\
\text { partners in past } 4 \text { weeks }\end{array}$ & 3.8 & 0.9 & 1.8 & 0.9 & 0.5 & $\mathrm{I} .4$ & 1.3 & 0.8 & 1.4 & $\mathrm{I} .4$ \\
\hline $\begin{array}{l}\text { Total female staff } \\
\text { at all establishments in cluster }\end{array}$ & 76 & 75 & 72 & 26 & 18 & 32 & 74 & 67 & 24 & 464 \\
\hline Establishment owners said & $9(82 \%)$ & II (85\%) & 7 (88\%) & $3(60 \%)$ & I (33\%) & $3(75 \%)$ & $10(100 \%)$ & $6(86 \%)$ & I (50\%) & 63 \\
\hline women meet new sex partners & $\mathrm{n}=\mathrm{II}$ & $n=13$ & $\mathrm{n}=8$ & $\mathrm{n}=5$ & $n=3$ & $n=4$ & $\mathrm{n}=10$ & $\mathrm{n}=7$ & $\mathrm{n}=2$ & \\
\hline Establishment owners said female & $4(50 \%)$ & $3(30 \%)$ & $4(44 \%)$ & I (20\%) & I (25\%) & I $(20 \%)$ & $6(75 \%)$ & $2(29 \%)$ & $0(0 \%)$ & 58 \\
\hline sex workers are present & $\mathrm{n}=8$ & $n=10$ & $n=9$ & $\mathrm{n}=5$ & $n=4$ & $n=5$ & $\mathrm{n}=8$ & $\mathrm{n}=7$ & $\mathrm{n}=2$ & \\
\hline $\begin{array}{l}\text { Establishment owners said female } \\
\text { staff meet new sex partners }\end{array}$ & $\begin{array}{l}4(80 \%) \\
n=5\end{array}$ & $\begin{array}{l}9(69 \%) \\
n=13\end{array}$ & $\begin{array}{l}6(86 \%) \\
n=7\end{array}$ & $\begin{array}{l}3(60 \%) \\
n=5\end{array}$ & $\begin{array}{l}2(50 \%) \\
n=4\end{array}$ & $\begin{array}{l}2(50 \%) \\
n=4\end{array}$ & $\begin{array}{l}7(70 \%) \\
n=10\end{array}$ & $\begin{array}{l}6(86 \%) \\
n=7\end{array}$ & $\begin{array}{l}2(100 \%) \\
n=2\end{array}$ & 57 \\
\hline
\end{tabular}

Note: ${ }^{2}$ Average of each bar's range of customers on busiest night. 


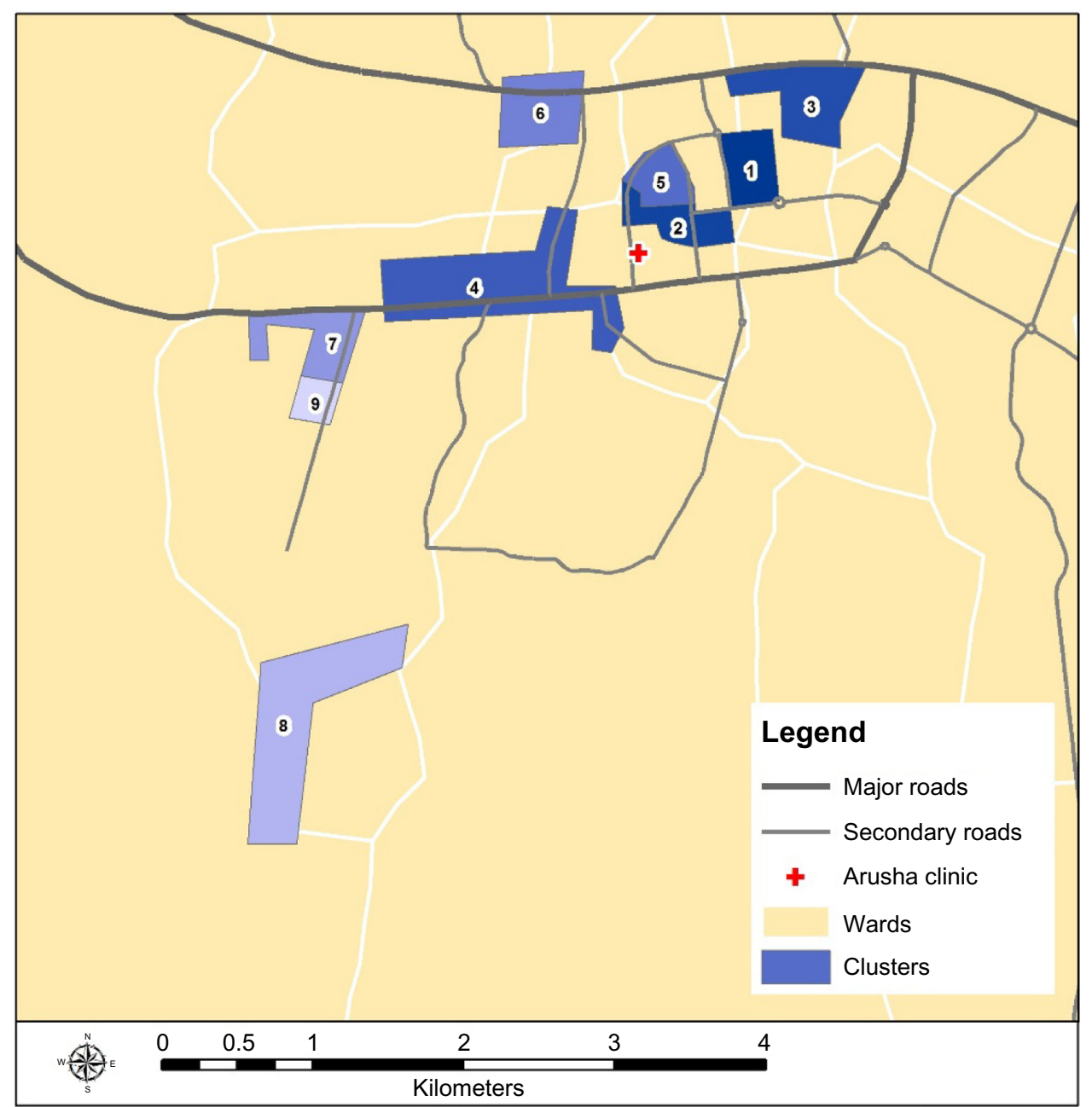

Figure 3 Establishment clusters by priority number.

Notes: Road network data created by OpenStreetMap, (C) OpenStreetMap contributors. ${ }^{28}$ Administrative boundary data accessed from DIVA-GIS. ${ }^{29}$

cluster A reported having a higher average number of sexual partners in the past 4 weeks (5.3 partners) compared with the total average number of sexual partners reported by women across the catchment area (2.8 partners), 2) women in cluster A reported having a higher number of new sexual partners in the past 4 weeks (3.8 partners) compared with the total average of women from all clusters (1.4 partners), 3) $82 \%$ of the owners $(n=11)$ in cluster A said women meet new sexual partners at their bars compared with the total average of $73 \%$, 4) four out of five bar owners in cluster A said that half or more of the women in their bars appear to be selling or buying sex compared with eight of the 52 bar owners in the entire survey, and 5) the largest total number of female employees (76) was located in cluster A (compared with a catchment area average of 52 staff). The remaining clusters were prioritized according to the frequencies of risk behaviors and total number of women working in or patronizing the establishments in the cluster, relative to the other clusters. Similar approaches were also used at the Pretoria site. In Bondo, priority areas were identified based on a combination of data from PLACE, the formative research, and staff experiences gained during the process of data collection.

\section{Implementation of the FEM-PrEP strategic recruitment plan}

The prioritized geographic areas identified during the formative research provided direction on where to focus recruitment approaches during the clinical trial. Various recruitment approaches were identified by site staff at the beginning of the trial, as described in standard operating procedures. These approaches included establishment-based recruitment (informed by PLACE data), recruitment at HIV testing and counseling (HTC) centers, and recruitment by peer educators. When recruitment began for the clinical trial, sites chose to 
conduct primarily establishment-based recruitment activities, as they believed it would be the most effective approach, and only in one or two prioritized establishment clusters at a time. Every month, the site recruitment teams assessed how beneficial the current recruitment strategy was by reviewing monthly reports of recruitment-related data and by reflecting upon their experiences over the past month.

The monthly recruitment reports consisted of a short summary of the recruitment activities and maps describing the following: 1) the geographic areas and establishment clusters where recruitment activities had occurred during the previous and past months, 2) the number of women who presented for screening by area/cluster, 3) the percentage of women who were HIV positive at screening by area/cluster, and 4) the geographic areas where women reported living and working. Decisions were then made about the recruitment strategy for the upcoming month, including whether to continue recruiting in the same establishment cluster, to move to the next prioritized establishment cluster, or to proceed with other prespecified recruitment activities (eg, recruiting at HTC centers and engaging peer recruiters).

Although incidence data from the specific geographic areas within the catchment area of the study clinic would have been the preferred information for making recruitment decisions, these data were unavailable. Therefore, we used screening prevalence data to gauge whether we could identify large numbers of uninfected women in the specific priority areas. For example, if a large percentage of the women who attended screening from one area were HIV positive, recruitment activities were likely to be moved to the next prioritized recruitment cluster due to a lack of eligible HIV-negative women. Similarly, very low screening prevalence in an area could indicate that the potential for HIV transmission might be too low, so recruitment activities might no longer be conducted there. Toward the end of the trial in the Bondo site, however, we conducted recruitment activities in the geographic areas where several trial participants who seroconverted lived or worked (preserving all confidential information), thereby focusing recruitment in areas where HIV transmission had been recently active.

\section{Lessons learnt}

\section{Lesson I: data were critical in identifying places presumed to be high risk}

Implementing the PLACE method allowed us to better identify and rank areas of potential high HIV risk compared with the initial recruitment areas identified by staff and the CAB. The initial ranking of high-risk areas identified by staff before data collection differed substantially from the priority areas rankings informed by the PLACE data and staff's experience from collecting the data. While staff in Bondo were quite familiar with the population in the study's catchment area and identified many of the same areas that were later confirmed by the PLACE data, the ranking of these areas was considerably different; some areas that staff presumed were areas of higher risk were found to be at presumed lower risk based on the PLACE data. However, the top recruitment priority area (ie, town center) was identified as highest risk by both staff in their initial list and PLACE data. In Pretoria, where staff were new to recruiting a population at higher risk for HIV, the initial staff lists included only very broad geographic locations, which differed considerably from the final priority areas. The PLACE data allowed us to identify smaller geographic areas and specific venues within the broader areas that were or were not of high risk. Likewise in Arusha, the initial staff lists included only broad areas, which were then subdivided into smaller, focused clusters and reprioritized using PLACE data.

\section{Lesson 2: staff experiences, \\ in combination with data, were needed} to inform a practical recruitment strategy Example I: including staff experiences from collecting the PLACE data enhanced the prioritization of establishment clusters

During data collection, recruitment staff became highly knowledgeable about the potential recruitment areas and provided valuable guidance on the feasibility of including some areas in the overall recruitment strategy. Using the PLACE data, we identified several rural bush areas in Pretoria as places where higher-risk activities occurred. Based on these data alone, these areas would have been ranked high on the priority list. However, based on staff's experience in collecting data from those areas, they determined that it would likely be challenging to sustain efficient, daily recruitment activities there because women do not generally gather in central locations (ie, taverns) but rather are individually scattered throughout the area. Additionally, staff learnt that some women found there migrate outside the catchment area. Therefore, we decided to conduct recruitment activities in these areas only once or twice per month, and to invite only those women who would remain in the catchment area to come for screening. In Bondo, an area identified to be at higher risk by the PLACE data was considered by site staff to be difficult to reach because it was an island that could be accessed only by hiring a boat from local fishermen for transportation. Staff's experience from collecting the PLACE data proved 
that traveling to this island would be too dangerous and time consuming to conduct future recruitment activities; therefore, it was no longer considered a priority area.

\section{Example 2: ensuring flexibility in implementing} recruitment activities in the priority areas during the trial was important for maintaining the recruitment momentum in broader geographic areas

Geographically adjacent areas were not always listed consecutively when priority areas were initially ranked using PLACE data alone. Once recruitment was underway, staff were concerned that moving recruitment activities to a geographic area far from the current priority area might hinder the overall recruitment momentum gained in the current area. For example, priority area 2 in Bondo was in the far west of the district, priority area 3 was in the far south, and priority area 4 was near priority area 2 . While conducting recruitment activities in priority area 2 , staff observed that many women from two neighboring priority areas (4 and 12) had heard about the trial and were presenting for screening. We therefore amended the priority list slightly so that areas that were geographically near one another were listed consecutively in order to continue recruitment efforts and promote the visibility of the recruitment team in the community.

\section{Lesson 3: recruiting in establishments in priority areas led to screening many HIV-positive women at the Bondo site, placing additional burden on clinic staff}

Recruitment activities in Bondo's priority areas were initially limited to recruiting only at establishments at night while providing community education to women's groups and market places during the day. During this time, the average monthly screening HIV prevalence rate was approximately $33 \%$. The associated high screen failure placed significant burden on the clinic staff due to higher than expected client volume necessary to meet the enrollment target. To mitigate this issue, we transitioned from establishment-based-only recruitment to recruiting only from study-sponsored HTC mobile units in the priority areas and nearby villages associated with those areas. HTC staff referred HIV-negative women aged 18-35 years and who also reported being sexually active recently (routine information collected during risk assessment of HTC clients, which overlapped with the trial's eligibility criteria) to the FEM-PrEP recruitment team, who then prescreened the women for other eligibility criteria (eg, not breastfeeding) before providing them with an appointment card for comprehensive screening at the clinic. This approach allowed recruitment activities to remain in the previously identified priority areas while focusing efforts only on women known to be HIV negative. Based on monthly site recruitment reports, during the final 7 months of recruitment, 2,047 women were tested for HIV at the HTC mobile unit, 963 were referred to the outreach team for prescreening, 575 were given a screening appointment to the clinic, and 532 were screened. Ultimately, referring women through the HTC mobile units and also prescreening them in the field reduced the number of ineligible women who came in to be screened for the trial at the study clinic (the monthly HIV-positive screen failure proportion was reduced to $4 \%$ ), which alleviated the added burden on clinic staff.

\section{Discussion}

Collecting PLACE data during the formative research phase not only helped us to identify places where women engaging in higher-risk behaviors could be found but also enhanced recruitment staff's knowledge of the catchment area. Without this data and staff experience, the trial's recruitment may have been conducted in areas where people did not engage in high-risk sexual behaviors or may have been conducted in areas otherwise unsuitable for recruitment. However, recruiting in places identified by the data overburdened site staff in one site because a high number of women who were HIV positive attended screening; transitioning to HCT referral from priority areas solved this issue. The flexible design of the recruitment plan allowed us to be responsive to the realities of trial logistics. The recruitment lessons learnt in the FEM-PrEP clinical trial highlight the critical importance of having a flexible and monitored recruitment strategy, as other studies have done in various ways. ${ }^{23-25}$

Although FEM-PrEP was unable to determine the effectiveness of FTC/TDF for HIV prevention, due to low adherence to the study product among participants, we successfully recruited a study population at higher risk for HIV. The incidence rate in the placebo arm was 4.7 per 100 personyears in Bondo and 6.0 per 100 person-years in Pretoria; no HIV end points occurred in Arusha due to early trial closure following initiation at that site. ${ }^{26}$

Moving forward, a similar approach using PLACE could be used in demonstration projects of proven HIV prevention products to identify and create demand among populations at high risk of HIV infection. Within biomedical HIV prevention trials of new study products, enrolling populations with sufficient HIV incidence will still remain an important factor. However, the effectiveness of a product can be determined in populations with lower incidence who also are highly adherent to the study product, as demonstrated in the Partners PrEP clinical trial. ${ }^{27}$ Ultimately, we must shift the paradigm of 
recruitment for clinical trials of new products from focusing on identifying populations with high incidence to identifying populations at risk who are motivated and able to adhere to the study product regimen.

\section{Acknowledgments}

FEM-PrEP recruitment group: Haddie Kiernan, Sarah Mullins, Zablon Omungo, Savi Chetty-Tulsee, Shumani Makatu, Saidi Kapiga, and Ross Malamatsho. We are grateful to the women who participated in the FEM-PrEP trial, to the study staff, to the communities who partnered with us to conduct the trial, as well as to all collaborators in Africa, Belgium, and the US. We also thank Kate MacQueen and Doug Taylor for their thorough review of this manuscript. FEM-PrEP was conducted under two grants funded by the United States Agency for International Development (USAID): the Contraceptive and Reproductive Health Technologies and Research Utilization Program and the Preventive Technologies Agreement No GHO-A-00-09-00016-00. Early support was also provided by the Bill and Melinda Gates Foundation. Gilead Sciences, Inc. donated FTC/TDF and placebo. The funding agencies and Gilead Science did not contribute to the study design, data collection and analysis, or writing of this manuscript. The views expressed in this publication do not necessarily reflect those of FHI 360, the funding agencies, or Gilead Sciences, Inc.

\section{Disclosure}

The authors report no conflicts of interest in this work.

\section{References}

1. Peterson L, Nanda K, Opoku BK, et al. SAVVY ${ }^{\circledR}(\mathrm{C} 31 \mathrm{G})$ gel for prevention of HIV infection in women: a phase 3, double-blind, randomized, placebo-controlled trial in Ghana. PloS One. 2007;2(12):e1312.

2. Feldblum PJ, Adeiga A, Bakare R, et al. SAVVY vaginal gel (C31G) for prevention of HIV infection: a randomized controlled trial in Nigeria. PloS One. 2008;3(1):e1474.

3. Halpern V, Ogunsola F, Obunge O, et al. Effectiveness of cellulose sulfate vaginal gel for the prevention of HIV infection: results of a Phase III trial in Nigeria. PloS One. 2008;3(11):e3784.

4. Skoler-Karpoff S, Ramjee G, Ahmed K, et al. Efficacy of Carraguard for prevention of HIV infection in women in South Africa: a randomised, double-blind, placebo-controlled trial. Lancet. 2008;372(9654): 1977-1987.

5. Gappoo S, Montgomery ET, Gerdts C, et al. Novel strategies implemented to ensure high participant retention rates in a community based HIV prevention effectiveness trial in South Africa and Zimbabwe. Contemp Clin Trials. 2009;30(5):411-418.

6. Ramjee G, Coumi N, Dladla-Qwabe N, et al. Research experiences in conducting multiple community-based HIV prevention trials among women in KwaZulu-Natal, South Africa. AIDS Res Ther. 2010;7:10.

7. Naidoo K. Screening for the VOICE Study at eThekwini site: lessons learnt and implications for retention in future studies. Presented at: the VOICE MTN Regional Meeting; Cape Town, South Africa; 2012.

8. Padian NS, van der Straten A, Ramjee G, et al. Diaphragm and lubricant gel for prevention of HIV acquisition in southern African women: a randomised controlled trial. Lancet. 2007;370(9583):251-261.
9. Djomand G, Metch B, Zorrilla CD, et al. The HVTN protocol 903 vaccine preparedness study: lessons learned in preparation for HIV vaccine efficacy trials. J Acquir Immune Defic Syndr. 2008;48(1):82-89.

10. Karim QA, Kharsany AB, Frohlich JA, et al. Recruitment of high risk women for HIV prevention trials: baseline HIV prevalence and sexual behavior in the CAPRISA 004 tenofovir gel trial. Trials. 2011;12(67):35.

11. Seyama L. Community engagement in HPTN 035 . Presented at: the Microbicide Trials Network Annual Meeting; Arlington, Virginia; 2009.

12. Koblin BA, Metch B, Novak RM, et al. Feasibility of identifying a cohort of US women at high risk for HIV infection for HIV vaccine efficacy trials: longitudinal results of HVTN 906. J Acquir Immune Defic Syndr. 2013;63(2):239-244.

13. Corneli A, Mack N, Kirkendale S; Truvada SBC Investigator and FHI Group. Socio-behavioral and community activities for an oral HIV prevention PrEP clinical trial: a multi-disciplinary approach. Presented at: the Microbicide Trials Network Annual Meeting; Delhi, India; 2008 .

14. Weir SS, Morroni C, Coetzee N, Spencer J, Boerma JT. A pilot study of a rapid assessment method to identify places for AIDS prevention in Cape Town, South Africa STI. 2002;78(Suppl 1):i106-i113.

15. Weir SS, Pailman C, Mahlalela X, Coetzee N, Meidany F, Boerma JT. From people to places: focusing AIDS prevention efforts where it matters most. AIDS. 2003;17(6):895-903.

16. Weir SS, Tate JE, Zhusupov B, Boerma JT. Where the action is: monitoring local trends in sexual behaviour. STI. 2004; 80 Suppl 2:ii63-ii68.

17. Wohl DA, Khan MR, Tisdale C, et al. Locating the places people meet new sexual partners in a southern US city to inform HIV/STI prevention and testing efforts. AIDS Behav. 2011;15(2):283-291.

18. Yamanis TJ, Maman S, Mbwambo JK, Earp JAE, Kajula LJ. Social venues that protect against and promote HIV risk for young men in Dar es Salaam, Tanzania. Soc Sci Med. 2010;71(9):1601-1609.

19. Brodish P, Singh K, Rinyuri A, et al. Evidence of high-risk sexual behaviors among injection drug users in the Kenya PLACE study. Drug Alcohol Depend. 2011;119(1):138-141.

20. Tate J, Singh K, Ndubani P, Kamwanga J, Buckner B. Measurement of HIV prevention indicators: a comparison of the PLACE method and a household survey in Zambia. AIDS Behav. 2010;14(1):209-217.

21. Speizer IS, Beauvais H, Gómez AM, Outlaw TF, Roussel B. Using multiple sampling approaches to measure sexual risk-taking among young people in Haiti: programmatic implications. Stud Fam Plann. 2009;40(4):277-288.

22. ESRI 2012. ArcGIS. Redlands, CA: Environmental Systems Research Institute.

23. Lovato LC, Hill K, Hertert S, Hunninghake DB, Probstfield JL. Recruitment for controlled clinical trials: literature summary and annotated bibliography. Control Clin Trials. 1997;18(4):328-352.

24. Ogunsola F, Halpern V, Obunge O, et al. Recruitment strategies in the Phase III randomized controlled trial of cellulose sulfate gel and HIV in Nigeria. Presented at: the International AIDS Conference; Mexico City, Mexico; 2008.

25. Gutiérrez-Luna A, Angeles-Llerenas A, Wirtz VJ, et al. Strategies and ethical considerations for the recruitment of young men who have sex with men: challenges of a vaccination trial in Mexico. Clin Trials. 2009;(4):365-372.

26. Van Damme L, Corneli A, Ahmed K, et al. Preexposure prophylaxis for HIV infection among African women. NEJM. 2012;367(5):411-422.

27. Baeten JM, Donnell D, Ndase P, et al. Antiretroviral prophylaxis for HIV prevention in heterosexual men and women. NEJM. 2012;367(5):399-410.

28. OpenStreetMap.org [homepage on the Internet]. OpenStreetMap. Available from: http://www.openstreetmap.org/\#map=5/51.509/7.603. Accessed October 29, 2014.

29. DIVA-GIS.org [homepage on the Internet]. DIVA-GIS. Available from: http://www.diva-gis.org/. Accessed October 29, 2014. 
Open Access Journal of Clinical Trials

Dovepress

\section{Publish your work in this journal}

The Open Access Journal of Clinical Trials is an international, peerreviewed, open access journal publishing original research, reports, editorials, reviews and commentaries on all aspects of clinical tria design, management, legal, ethical and regulatory issues, case record form design, data collection, quality assurance and data auditing methodologies. The manuscript management system is completely online and includes a very quick and fair peer-review system, which is all easy to use. Visit http://www.dovepress.com/testimonials.php to read real quotes from published authors.

Submit your manuscript here: http://www.dovepress.com/open-access-journal-of-clinical-trials-journal 